\title{
Comparison of the functional and radiological outcomes of vascularized and non-vascularized bone graft options in the treatment of scaphoid nonunion
}

\author{
Mert Kahraman Maraşlı, MD (i), Birkan Kibar, MD (i), Ali Cavit, MD (1) \\ Department of Orthopedics and Traumatology, Istanbul Haydarpaşa Numune Training and Research Hospital, Istanbul, Turkey
}

\begin{abstract}
Scaphoid fractures represent 50 to $80 \%$ of all carpal fractures, with the greatest incidence among young and active males. ${ }^{[1-3]}$ A scaphoid nonunion (SN) is defined as an unhealed fracture six months after injury and the nonunion rate after a scaphoid fracture is relatively high. Numerous bone grafting techniques have been proposed for the treatment of SN. The differences between these techniques include the harvest site of the bone graft and the use of a vascularized bone graft (VBG) or a non-vascularized bone graft (NVBG). ${ }^{[4]}$ Vascularized bone grafts, such as the 1,2-intercompartmental supraretinacular artery pedicled VBG (1,2-ICSRA-VBG), the volar carpal artery pedicled flap, the pronator quadratus (PQ) pedicled flap and the free medial femoral condyle (MFC) graft have become increasingly popular in the treatment of SN. ${ }^{[4-6]}$ 1,2-ICSRA-VBG method was first used in 1991 by Zaidemberg et al. ${ }^{[7]}$ and was the most commonly
\end{abstract}

Received: July 19, 2021

Accepted: October 15, 2021

Published online: November 19, 2021

Correspondence: Mert Kahraman Maraşlı, MD. Haydarpaşa Numune Eğitim ve Arasstırma Hastanesi Ortopedi ve Travmatoloji Kliniği, 34668 Üsküdar, İstanbul, Türkiye.

E-mail: mertmarasli.md@gmail.com

\section{Doi: $10.52312 / j d r s .2021 .354$}

Citation: Maraşlı MK, Kibar B, Cavit A. Comparison of the functional and radiological outcomes of vascularized and nonvascularized bone graft options in the treatment of scaphoid nonunion. Jt Dis Relat Surg 2021;32(3):736-743.

\section{(C2021 All right reserved by the Turkish Joint Diseases Foundation}

This is an open access article under the terms of the Creative Commons Attribution-NonCommercial License, which permits use, distribution and reproduction in any medium, provided the original work is properly cited and is not used for commercial purposes (http://creativecommons.org/licenses/by-nc/4.0/).

\section{ABSTRACT}

Objectives: This study aims to compare the functional and radiological outcomes of the patients with scaphoid waist nonunion treated with non-vascularized bone graft and vascularized bone graft options.

Patients and methods: Between January 2016 and February 2020 , a total of 24 patients (22 males, 2 females; mean age: $30.6 \pm 9.4$ years; range, 18 to 66 years) with scaphoid waist nonunion who were treated with vascularized or non-vascularized bone graft were retrospectively analyzed. Of these patients, eight were treated with iliac crest non-vascularized bone graft (IC-NBG), seven with vascularized free medial femoral condyle (MFC) graft, and nine with 1,2-intercompartmental supraretinacular artery pedicled vascularized bone graft (1,2-ICSRA-VBG). The grip strength, flexion, extension, radial deviation, ulnar deviation angles were measured and compared to the contralateral hand for functional outcomes. Union rates, the scaphoid height-to-length ratio, the lateral intrascaphoid angle (LISA) were evaluated for radiological outcomes. The Mayo Wrist Score, Visual Analog Scale (VAS) score, and Quick Disability of the Arm, Shoulder and Hand (Q-DASH) Questionnaire score were calculated.

Results: Union was observed in seven $(87.5 \%)$ patients after IC-NBG, in six (85.7\%) patients after MFC bone graft and nine $(100 \%)$ patients in the treatment group with 1,2-ICSRA-VBG. There were no statistically significant differences among the IC-NBG, MFC and 1,2-ICSRA-VBG groups in terms of the union rates, the scaphoid height-to-length ratio, VAS score, Q-DASH score, grip strength and flexion, ulnar deviation, radial deviation angles after surgery $(\mathrm{p}>0.05)$. However, extension was statistically lower in the MFC group than IC-NBG and 1,2-ICSRA-VBG groups after surgery. The Mayo score was better in the IC-NBG group than MFC and 1,2-ICSRA-VBG, indicating a statistically significant difference $(\mathrm{p}<0.05)$.

Conclusion: Based on our study results, we suggest to use IC-NBG for scaphoid waist nonunion as the primary procedure, as the union rates are comparable with the MFC and 1,2-ICSRA-VBG techniques and it has advantages such as shorter operation time, easier technique, no special experience requirement, and better functional outcomes.

Keywords: Scaphoid bone grafting, scaphoid nonunion, scaphoid nonvascularized bone graft, scaphoid pseudoarthrosis, scaphoid vascularized bone graft. 
used method in recent times. The use of MFC was first described by Doi et al. ${ }^{[8]}$ who reported successful union rates in all 10 patients at an average of 12 weeks after the procedure.

Although treatment strategies for $\mathrm{SN}$ remain controversial, conventional NVBGs, such as iliac crest non-vascularized bone graft (IC-NBG) are still commonly performed. ${ }^{[9-11]}$ However, the comparison of vascularized versus NVBG for the treatment of SN is limited..$^{[12,13]}$ In the present study, we aimed to analyze scaphoid waist nonunion patients who had no avascular necrosis and no prior surgical treatment for scaphoid fracture and were treated with a vascularized (1,2-ICSRA-VBG and MFC) and NVBG (IC-NBG).

\section{PATIENTS AND METHODS}

This single-center, retrospective study was conducted at Istanbul Haydarpaşa Numune Training and Research Hospital, Department of Orthopedics and Traumatology between January 2016 and February 2020. Inclusion criteria were as follows: scaphoid waist nonunion diagnosed by computed tomography (CT) and X-ray; treatment with vascularized (1,2-ICSRA-VBG and MFC) or non-vascularized (IC-NBG) bone graft; at least oneyear of postoperative follow-up. Exclusion criteria were as follows: loss to follow-up; having other injury at the ipsilateral extremity or contralateral upper extremity; having caused by pathological fractures or open fracture. Patients who met the inclusion criteria were called by phone: seven patients could not be reached and five patients did not attend.
Finally, a total of 24 patients (22 males, 2 females; mean age: $30.6 \pm 9.4$ years; range, 18 to 66 years) were included. A written informed consent was obtained from each patient. The study protocol was approved by the Istanbul Haydarpasa Numune Training and Research Hospital Ethics Committee (No. HNEAH-KAEK 2021/KK/90 Istanbul, Turkey). The study was conducted in accordance with the principles of the Declaration of Helsinki.

\section{Surgical procedures}

All surgeries were performed as described previously. ${ }^{[7,9,10,13,14]}$ All three surgical techniques were performed by three hand surgeons. The choice of surgical technique was based on the surgeons' individual previous experience.

Eight scaphoid waist nonunions were treated with a vascularized distal radial bone graft based on 1,2-ICSRA-VBG pedicle (Figure 1). A longitudinal incision was made on the radiodorsal side of the wrist. The longitudinal course of the irrigating vessel was easily seen over the distal radius. A VBG was placed and this perfusing periosteal blood vessel was centered over the bone to be harvested. Next, the nonunion of the scaphoid was visualized and the sclerotic bone ends were refreshed. A bone graft was, then, taken from the distal radius, lying under the vascular pedicle, and its size corresponded to the cavity created in the scaphoid.

Seven scaphoid waist nonunions were treated with MFC bone graft (Figure 2). A medial incision was made over the MFC. The descending genicular vessels were located proximally on the floor of
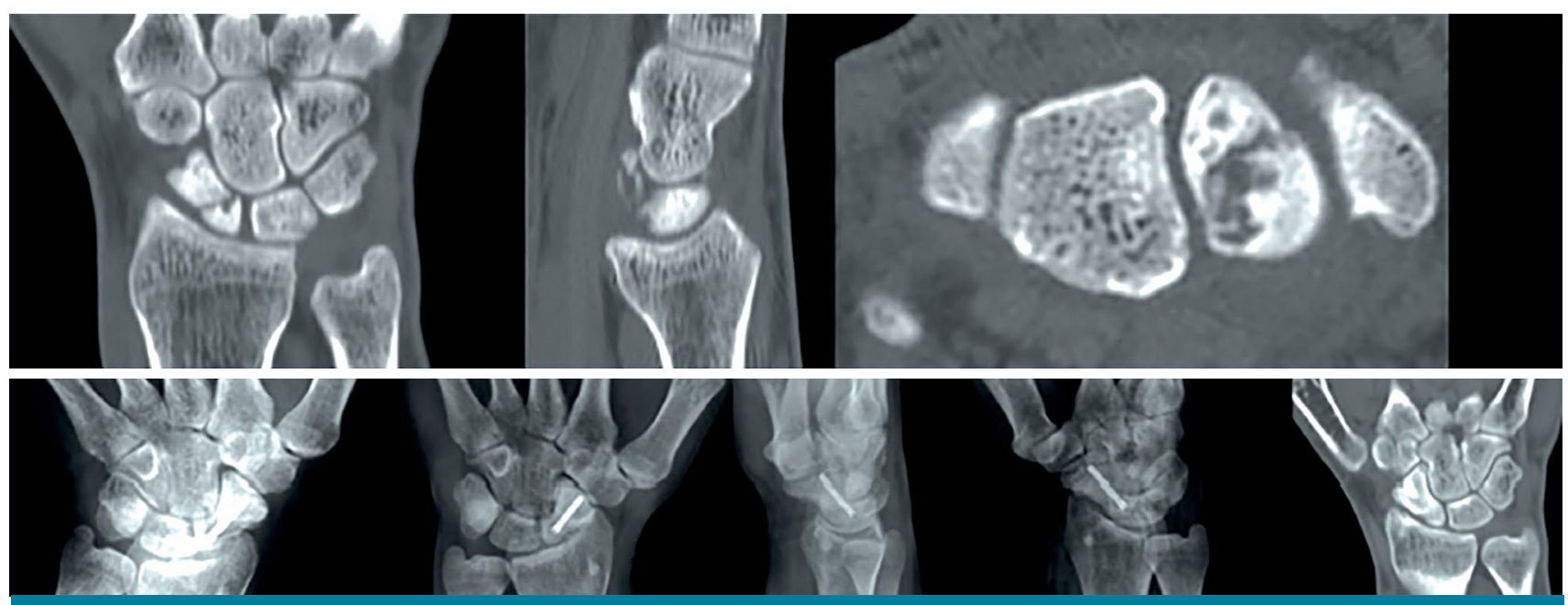

FIGURE 1. A 33-year-old male with scaphoid waist nonunion. The 1,2-ICSRA-VBG was used in this patient. Preoperative coronal, sagittal, axial CT images and T1- coronal MRI and the postoperative X-rays and CT images at two years after surgery.

1,2-ICSRA-VBG: 1,2-intercompartmental supraretinacular artery pedicled vascularized bone graft; CT: Computed tomography; MRI: Magnetic resonance imaging. 

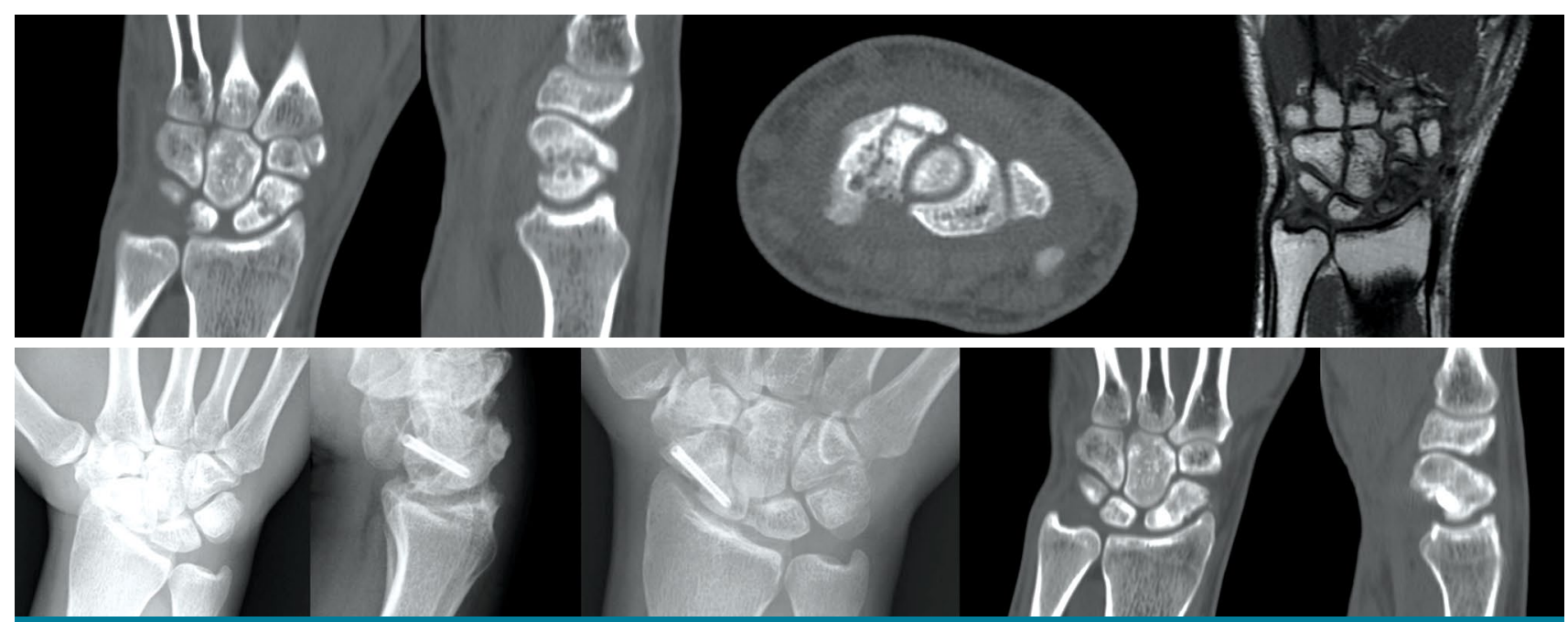

FIGURE 2. A 28-year-old male with scaphoid waist nonunion. The MFC bone graft was used in this patient. Preoperative coronal, sagittal, axial CT images and T1-coronal MRI and the postoperative X-rays and CT images at two years after surgery.

MFC: Medial femoral condyle; CT: Computed tomography; MRI: Magnetic resonance imaging.

the muscle compartment and distally on the MFC. After identifying the vessels to be used as pedicles on the medial condyle, the graft was outlined on the periosteum. A standard volar Russe approach was applied to the scaphoid. Fibrous tissues in the nonunion field were resected, and the sclerotic bone ends were refreshed. The harvested MFC graft, which was larger than the defect, was formed into a wedge or trapezoid shape, trimmed and placed in the defect. The descending genicular artery was anastomosed to the radial artery in an end-to-side fashion, and a concomitant vein was anastomosed to a radial venae comitantes or a superficial vein in an end-to-end fashion.
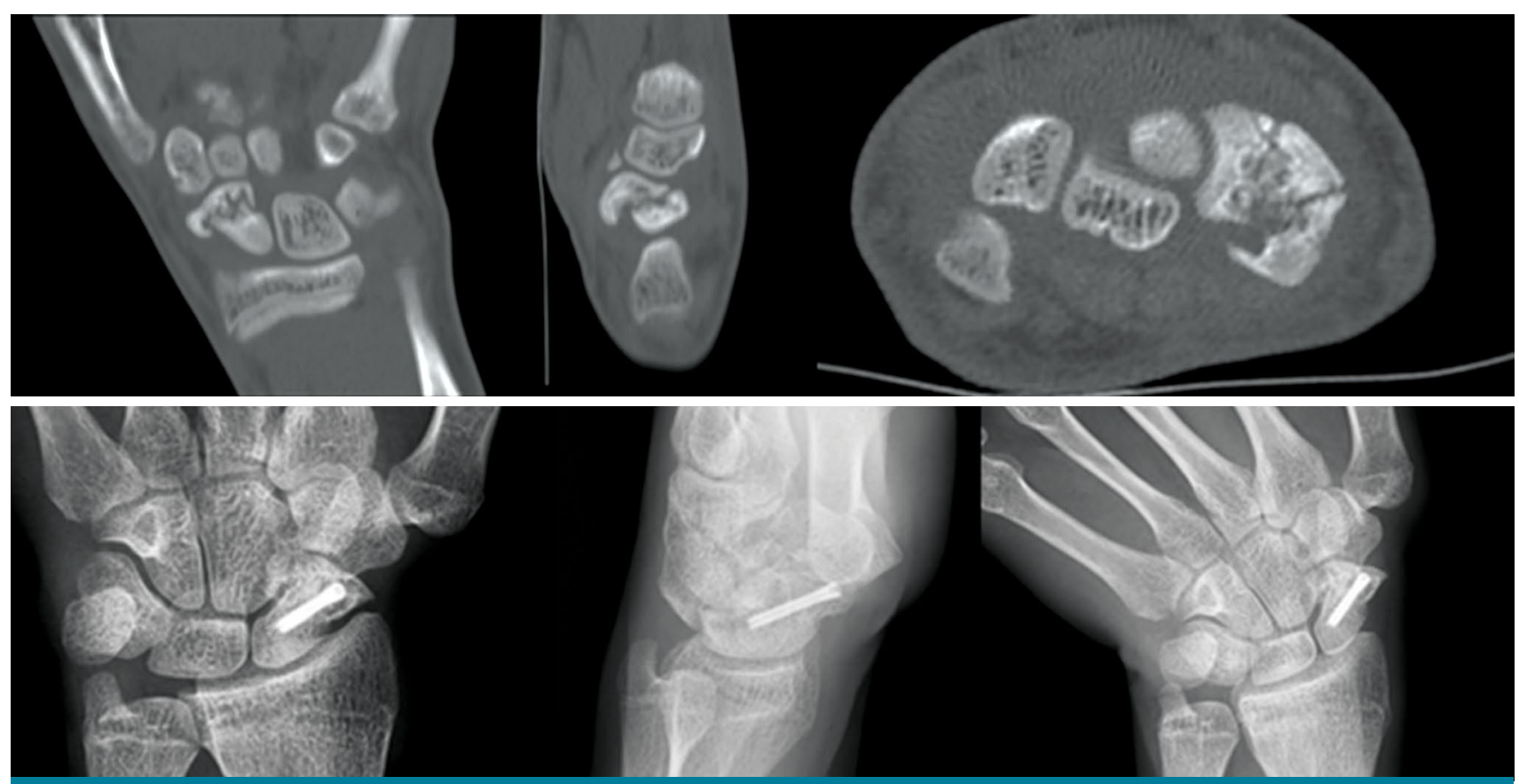

FIGURE 3. A 20-year-old male with scaphoid waist nonunion was treated with an IC-NBG. Preoperative coronal, sagittal, axial CT images and the postoperative $\mathrm{X}$-rays at two years after surgery.

IC-NBG: Iliac crest non-vascularized bone graft; CT: Computed tomography. 
Nine scaphoid waist nonunions were treated with IC-NBG (Figure 3). A standard volar russe approach was chosen for the scaphoid. The nonunion site was, then, prepared to receive a corticocancellous interpositional graft taken from the iliac crest.

After insertion of the graft, internal fixation was performed with a headless compression screw. A single type of compression screw $(3.5 \mathrm{~mm}$, headless, cannulated and full threaded) (Suzhou Youbetter Medical Apparatus Co. Ltd., Jiangsu, China) was used in all 24 patients.

After surgery, the wrist was immobilized for six weeks in a short-arm thumb spica cast that left the interphalangeal joint of the thumb free. After removal of the cast, active assisted motion exercises were allowed. The patients who could not achieve full range of motion were referred to physiotherapists in our hospital. The patients were followed at 2, 4, 6, and 12 weeks after surgery and monthly thereafter, until the bony union of the scaphoid was confirmed.

\section{Assessment}

Prior to surgery, four different views of radiographs (wrist anteroposterior [AP], AP with ulnar deviation, oblique, lateral), (CT), and magnetic resonance imaging (MRI) of the wrist were performed. Radiological and clinical examinations were routinely performed at 2, 4, 6, and 12 weeks after surgery and during the final follow-up visit. Postoperative radiological measurements and functional evaluations collected at the final followup were analyzed. On postoperative radiographs, the lateral intrascaphoid angle (LISA) and scaphoid height-to-length ratio were measured on sagittal CT images by two hand surgeons. Functional examination of all patients was performed by a single-blinded physiotherapist who was not involved in the surgical treatment. Wrist ranges of motion in extension, flexion, radial and ulnar deviation from the neutral position were measured with a goniometer. Grip strength was measured with a Jamar dynamometer (Sammons Preston Rolyan, Chicago, USA) and was compared with the contralateral side.

Wrist pain was rated using a Visual Analog Scale (VAS $0=$ no pain, $100=$ severe pain). The functional subjective outcome was assessed with the Quick Disability of the Arm, Shoulder and Hand (Q-DASH) Questionnaire and Mayo Wrist Score. The Turkish validated versions of the VAS and Q-DASH were used. ${ }^{[15,16]}$

\section{Statistical analysis}

Statistical analysis was performed using the IBM SPSS version 22.0 software (IBM Corp., Armonk, NY, USA). Continuous variables were expressed in mean \pm standard deviation (SD), while categorical variables were expressed in number and frequency. The Student t-test or Wilcoxon rank-sum test was used to normally distributed continuous variables. To compare the differences among groups, one-way analysis of variance (ANOVA) or Kruskal-Wallis $\mathrm{H}$ test was used for continuous variables, while the chi-square test was used for categorical variables. The Pearson and Spearman correlation tests were used for correlation analysis. A two-sided $p$ value of $<0.05$ was considered statistically significant.

\section{RESULTS}

\section{Demographics}

The mean follow-up was $27.1 \pm 13.5$ (range, 24 to 54 ) months. Fourteen of $24(58.3 \%)$ patients were smokers. The right side was injured in $12(50 \%)$ and the left in $12(50 \%)$ patients. Ten of the fractures were on the dominant hand $(41.6 \%)$. The duration of nonunion was known in 17 patients, in whom the mean time to surgery was 25 months ( 7 months to 10 years). The duration of nonunion was unknown in seven patients. There was no statistically significant difference among the groups for age, sex, and smoking. Demographic and clinical characteristics of the patients are summarized in Table I.

Union was observed in seven (87.5\%) patients after IC-NBG, in six (85.7\%) patients after MFC bone graft, and in nine $(100 \%)$ patients in the treatment group with 1,2-ICSRA-VBG (Table II). There was no statistically significant difference in the union rates $(\mathrm{p}>0.05)$.

Grip strength, extension, flexion, radial deviation and ulnar deviation after surgery were evaluated in comparison to the contralateral hand and among the groups. All functional and radiological outcomes of the patients are summarized in Table II.

Extension was statistically lower in the MFC group than the IC-NBG and 1,2-ICSRA-VBG groups postoperatively $(\mathrm{p}=0.03)$. There was no statistically significant difference among the IC-NBG, MFC and 1,2-ICSRA-VBG groups in terms of union rates, the scaphoid height-to-length ratio, VAS score, Q-DASH score, grip strength and flexion, ulnar deviation, radial deviation angles postoperatively. Although there was no statistically significant difference in the grip strength at surgery compared to the contralateral uninjured side with IC-NBG group $(p=0.57)$, there was 
TABLE I

Characteristics of patients

\begin{tabular}{|c|c|c|c|c|c|c|c|c|c|c|c|c|}
\hline \multirow[b]{2}{*}{ Characteristics } & \multicolumn{3}{|c|}{ Total $(n=24)$} & \multicolumn{3}{|c|}{ IC-NBG $(n=8)$} & \multicolumn{3}{|c|}{ MFC $(n=7)$} & \multicolumn{3}{|c|}{ 1,2-ICSRA-VBG $(n=9)$} \\
\hline & $\mathrm{n}$ & $\%$ & Mean $\pm S D$ & $\mathrm{n}$ & $\%$ & Mean \pm SD & $\mathrm{n}$ & $\%$ & Mean \pm SD & $\mathrm{n}$ & $\%$ & Mean $\pm S D$ \\
\hline Age (year) & & & $30.6 \pm 9.4$ & & & $28.9 \pm 7.6$ & & & $28.4 \pm 10.8$ & & & $33.9 \pm 9.76$ \\
\hline \multicolumn{13}{|l|}{ Sex } \\
\hline Female & 2 & 8.3 & & 2 & 25 & & 0 & 0 & & 0 & 0 & \\
\hline Male & 22 & 91.7 & & 6 & 75 & & 7 & 100 & & 9 & 100 & \\
\hline \multicolumn{13}{|l|}{ Smoker } \\
\hline Yes & 14 & 58.3 & & 5 & 62.5 & & 5 & 71.4 & & 6 & 33.3 & \\
\hline No & 10 & 41.7 & & 3 & 37.5 & & 2 & 28.6 & & 3 & 66.7 & \\
\hline \multicolumn{13}{|l|}{ Injured hand } \\
\hline Dominant & 10 & 41.7 & & 4 & 50 & & 5 & 71.4 & & 1 & 11.8 & \\
\hline Nondominant & 14 & 58.3 & & 4 & 50 & & 2 & 28.6 & & 8 & 88.9 & \\
\hline Right & 12 & 50 & & 5 & 62.5 & & 6 & 85.7 & & 1 & 11.8 & \\
\hline Left & 12 & 50 & & 3 & 37.5 & & 1 & 14.3 & & 8 & 88.9 & \\
\hline Follow-up (months) & & & $27.1 \pm 13.5$ & & & $42.2 \pm 7.6$ & & & $25.2 \pm 3.5$ & & & $15.0 \pm 2.3$ \\
\hline
\end{tabular}

\section{TABLE II}

Functional and radiological outcomes

\begin{tabular}{|c|c|c|c|c|c|c|c|c|}
\hline \multirow[b]{2}{*}{ Outcomes } & \multirow[b]{2}{*}{$\begin{array}{l}\text { Comparation to the } \\
\text { CL side }\end{array}$} & \multicolumn{2}{|c|}{ IC-NBG $(n=8)$} & \multicolumn{2}{|c|}{ MFC $(n=7)$} & \multicolumn{2}{|c|}{ 1,2-ICSRA-VBG $(n=9)$} & \multirow[b]{2}{*}{$p$} \\
\hline & & $\%$ & Mean \pm SD & $\%$ & Mean $\pm S D$ & $\%$ & Mean $\pm S D$ & \\
\hline \multirow[t]{2}{*}{ Union rates (\%) } & & 87.5 & & 85.7 & & 100 & & 0.511 \\
\hline & Postoperative & & $86.6 \pm 19.5$ & & $87.2 \pm 22.7$ & & $83.3 \pm 19.2$ & 0.918 \\
\hline \multirow[t]{3}{*}{ Grip strength (kg) } & $\mathrm{CL}$ & & $90.6 \pm 19.7$ & & $101.4 \pm 16.0$ & & $110.5 \pm 16.5$ & 0.087 \\
\hline & Compared $p$ value & & 0.57 & & 0.01 & & 0.005 & \\
\hline & Postoperative & & $73.1 \pm 9.9$ & & $55.1 \pm 20.1$ & & $65.4 \pm 22.9$ & 0.191 \\
\hline \multirow[t]{3}{*}{ Flexion (degree) } & $\mathrm{CL}$ & & $79.3 \pm 9.7$ & & $66.4 \pm 18.8$ & & $80.7 \pm 8.6$ & 0.078 \\
\hline & Compared $p$ value & & 0.18 & & 0.12 & & 0.07 & \\
\hline & Postoperative & & $61.6 \pm 12.4$ & & $42.2 \pm 21.5$ & & $61.8 \pm 12.7$ & 0.032 \\
\hline \multirow[t]{3}{*}{ Extension (degree) } & $\mathrm{CL}$ & & $70.1 \pm 4.8$ & & $59.0 \pm 22.7$ & & $75.3 \pm 16.6$ & 0.153 \\
\hline & Compared $p$ value & & 0.18 & & 0.02 & & 0.08 & \\
\hline & Postoperative & & $19.1 \pm 9.1$ & & $10.7 \pm 7.3$ & & $18.7 \pm 11.1$ & 0.172 \\
\hline \multirow[t]{3}{*}{ Radial deviation (degree) } & $\mathrm{CL}$ & & $28.0 \pm 8.7$ & & $25.7 \pm 8.9$ & & $33.7 \pm 12.0$ & 0.286 \\
\hline & Compared $p$ value & & 0.03 & & 0.002 & & 0.012 & \\
\hline & Postoperative & & $46.8 \pm 7.5$ & & $32.1 \pm 17.9$ & & $43.1 \pm 11.9$ & 0.083 \\
\hline \multirow[t]{2}{*}{ Ulnar deviation (degree) } & $\mathrm{CL}$ & & $73.1 \pm 9.9$ & & $55.1 \pm 20.1$ & & $65.4 \pm 22.9$ & 0.359 \\
\hline & Compared $p$ value & & 0.72 & & 0.08 & & 0.13 & \\
\hline Height-to-length ratio & & & $0.55 \pm 0.12$ & & $0.51 \pm 0.14$ & & $0.61 \pm 0.12$ & 0.272 \\
\hline LISA (degree) & & & $45 \pm 13.2$ & & $27.3 \pm 8.1$ & & $29.4 \pm 17.1$ & 0.031 \\
\hline Mayo Wrist score & & & $83.7 \pm 10.2$ & & $72.8 \pm 10.3$ & & $72.7 \pm 7.5$ & 0.041 \\
\hline VAS score & & & $10.0 \pm 11.9$ & & $17.1 \pm 24.2$ & & $30.0 \pm 22.3$ & 0.141 \\
\hline Q-DASH score & & & $5.9 \pm 14.3$ & & $13.9 \pm 26.8$ & & $16.2 \pm 22.6$ & 0.613 \\
\hline
\end{tabular}

SD: Standard deviation; IC-NBG: Iliac crest non-vascularized bone graft; MFC: Medial femoral condyle; 1,2-ICSRA-VBG: 1,2-intercompartmental supraretinacular artery pedicled vascularized bone graft; CL: Contralateral; LISA: Lateral intrascaphoid angle; VAS: Visual Analog Scale; Q-DASH: Quick Disability of the Arm, Shoulder and Hand Questionnaire. 
a significant difference in the MFC group $(p=0.01)$ and the 1,2-ICSRA-VBG group $(p=0.005)$. There was a statistically significant decrease in the radial deviation of the wrist achieved by surgery compared to the contralateral uninjured side with the IC-NBG, MFC and 1,2-ICSRA-VBG groups ( $\mathrm{p}=0.03, \mathrm{p}=0.012$, and $\mathrm{p}=0.002$, respectively).

The Mayo score was better in the IC-NBG group than MFC and 1,2-ICSRA-VBG groups and the differences were statistically significant $(p=0.03)$. The LISA was statistically significant higher in the IC-NBG group than the MFC and 1,2-ICSRA-VBG groups $(\mathrm{p}=0.03)$.

There was a moderate, negative and a statistically significant correlation between the Mayo scores and the Q-DASH scores $(\mathrm{p}=0.009)$. There was also a very strong, positive and statistically significant correlation between the Q-DASH scores and the VAS scores $(p<0.001)$. In addition, there was a strong, negative, and statistically significant correlation between the Mayo scores and the VAS score $(\mathrm{p}<0.001)$.

\section{DISCUSSION}

The main goals of scaphoid reconstruction are to achieve union and restore normal carpal anatomy, stability and range of motion. Although several treatment options have been suggested for the nonunion of the scaphoid, no consensus has been reached on the most optimal treatment option yet. In our clinic, a consensus on the ideal treatment option regarding the primary treatment strategy for scaphoid waist nonunion has not been reached, either. It depends on the surgeons' experiences and discretions. Although the most common indication for the use of VBGs is prior unsuccessful NVBG applications, the recent literature also supports the use of VBGs as the primary procedure in the treatment of SN. ${ }^{[17]}$ Similarly, all patients in our study never underwent surgical treatment previously. Therefore, we attempted to compare the outcomes of the three techniques in the primary treatment of scaphoid waist nonunion. To the best of our knowledge, this is the first study to compare IC-NBG, MFC bone graft and 1,2-ICSRA-VBG for the primary treatment of scaphoid waist nonunion.

Theoretically, VBGs have the benefit of keeping osteoblasts and osteocytes alive. Different surgical techniques have been proposed to increase the union rate. Meta-analyses comparing NVBGs and VBGs in the treatment of SN failed to show a significant difference in union rates. In a recent systematic review by Pinder et al. ${ }^{[12]}$ involving
1,602 patients, the union rate was $88 \%$ for NVBGs and $92 \%$ for VBGs, but it did not reach statistical significance. In our study, the differences regarding the union rates were not statistically significant, either.

In the present study, compared to the contralateral uninjured side with the IC-NBG group, there was no statistically significant difference in the grip strength at surgery, indicating that the grip strength achieved by surgery in the IC-NBG group was similar to that on the uninjured side. However, in the MFC group and the 1,2-ICSRA-VBG group, the grip strength with the operated hand decreased significantly compared to the uninjured side.

Braga-Silva et al. ${ }^{[1]}$ found no statistically significant difference between the 1,2-ICSRA-VBG and IC-NBG compared to the contralateral side in terms of grip strength and similar results for range of motion values. In our study, it was $96 \%$ of the grip strength of the healthy side in the IC-NBG group. In contrast, it was $85 \%$ of the grip strength of the healthy side in the MFC group and only $75 \%$ in the 1,2-ICSRA-VBG group. Our study indicates that IC-NBG is better than MFC and 1,2-ICSRA-VBG in preventing grip strength.

On the other hand, there was a significant difference in radial deviation of the wrist at achieved surgery compared to contralateral uninjured side in all three groups in our study $(p=0.03, p=0.02$, and $\mathrm{p}=0.01$, respectively). This finding suggests that radial deviation was significantly restricted after SN surgery in all three surgical options. Additionally, there was a significant difference in the wrist extension after surgery compared to the contralateral uninjured side in the MFC group ( $p=0.002)$, while there was no significant difference in the other two groups ( $p>0.05$ ).

The Mayo score was significantly higher in the IC-NBG group than in the MFC and 1,2-ICSRA-VBG groups $(\mathrm{p}=0.04)$. Likewise, the Q-DASH score and VAS score were lower in the IC-NBG group than in the MFC and 1,2-ICSRA-VBG groups, although not statistically significant $(\mathrm{p}=0.61$ and $\mathrm{p}=0.14$, respectively). Hirche et al. ${ }^{[18]}$ found similar results on the Mayo score between vascularized graft group and non-vascularized graft group. Our study showed better functional outcomes in the IC-NBG group. Moreover, the LISA was significantly higher in the IC-NBG group than in the MFC and 1,2-ICSRA-VBG groups in our study $(\mathrm{p}=0.03)$.

When a vascularized graft is used, consolidation occurs through normal fracture resolution; as a result of the providing osteogenic, osteoinductive 
and osteoconductive stimuli, that more appropriately support biomechanical loading to achieve and rapid consolidation. ${ }^{[19,20]}$ In contrast, the use of a NVBG promotes consolidation through a substitution process, by providing a "scaffold", instead of living tissue. ${ }^{[20]}$ In our study, the scaphoid height-to-length ratio in all three groups was consistent with the normal value in the literature and there were no statistically significant differences among the groups. It has been suggested that all three techniques are good at preventing the scaphoid construction. However, no consensus on the normal value of LISA has been reached in the literature. ${ }^{[21]}$

Although some studies obtained no satisfactory results in patients treated with NVBG and screw fixation for scaphoid non-unions, recent meta-analyses have shown that, despite a higher union rate and earlier union with the VBG technique, this radiological advantage does not provide any functional benefits. ${ }^{[22,23]}$ Additionally, VBGs are technically more difficult and need more surgical experience. The IC-NBG is widely used as a standard technique and provides relatively large volumes and relatively easy to harvest grafts with good biomechanical properties. In the present study, better outcomes could be obtained with the IC-NBG for SN.

The main limitations of this study are its single-center and retrospective design with a relatively small sample size. In addition, the choice of surgical technique was determined by the surgeons' experience and discretion. Further large-scale, prospective studies are needed to confirm these findings.

In conclusion, we suggest to use IC-NBG for scaphoid waist nonunion as the primary procedure, as it is easier, does not require special experience, and has better functional outcomes. We do not recommend MFC bone graft for primary treatment of scaphoid waist nonunion, since the operation is longer, more difficult, and requires microsurgical techniques with poor outcomes.

\section{Declaration of conflicting interests}

The authors declared no conflicts of interest with respect to the authorship and/or publication of this article.

\section{Funding}

The authors received no financial support for the research and/or authorship of this article.

\section{REFERENCES}

1. Alshryda S, Shah A, Odak S, Al-Shryda J, Ilango B, Murali SR. Acute fractures of the scaphoid bone: Systematic review and meta-analysis. Surgeon 2012;10:218-29.
2. Sendher R, Ladd AL. The scaphoid. Orthop Clin North Am 2013;44:107-20.

3. Acar B, Köse Ö, Turan A, Katı YA, Güler F. Single versus double screw fixation for the treatment of scaphoid waist fractures: Finite element analysis and preliminary clinical results in scaphoid nonunion. Jt Dis Relat Surg 2020;31:73-80.

4. Rahimnia A, Rahimnia AH, Mobasher-Jannat A. Clinical and functional outcomes of vascularized bone graft in the treatment of scaphoid non-union. PLoS One 2018;13:e0197768.

5. Ditsios K, Konstantinidis I, Agas K, Christodoulou A. Comparative meta-analysis on the various vascularized bone flaps used for the treatment of scaphoid nonunion. J Orthop Res 2017;35:1076-85.

6. Bürger HK, Windhofer C, Gaggl AJ, Higgins JP. Vascularized medial femoral trochlea osteocartilaginous flap reconstruction of proximal pole scaphoid nonunions. J Hand Surg Am 2013;38:690-700.

7. Zaidemberg C, Siebert JW, Angrigiani C. A new vascularized bone graft for scaphoid nonunion. J Hand Surg Am 1991;16:474-8.

8. Doi K, Oda T, Soo-Heong T, Nanda V. Free vascularized bone graft for nonunion of the scaphoid. J Hand Surg Am 2000;25:507-19.

9. Fernandez DL. A technique for anterior wedge-shaped grafts for scaphoid nonunions with carpal instability. J Hand Surg Am 1984;9:733-7.

10. Fernandez DL. Anterior bone grafting and conventional lag screw fixation to treat scaphoid nonunions. J Hand Surg Am 1990;15:140-7.

11. Braga-Silva J, Peruchi FM, Moschen GM, Gehlen D, Padoin AV. A comparison of the use of distal radius vascularised bone graft and non-vascularised iliac crest bone graft in the treatment of non-union of scaphoid fractures. J Hand Surg Eur Vol 2008;33:636-40.

12. Pinder RM, Brkljac M, Rix L, Muir L, Brewster M. Treatment of scaphoid nonunion: A systematic review of the existing evidence. J Hand Surg Am 2015;40:1797-805.e3.

13. Jones DB Jr, Bürger H, Bishop AT, Shin AY. Treatment of scaphoid waist nonunions with an avascular proximal pole and carpal collapse. Surgical technique. J Bone Joint Surg Am 2009;91 Suppl 2:169-83.

14. Larson AN, Bishop AT, Shin AY. Free medial femoral condyle bone grafting for scaphoid nonunions with humpback deformity and proximal pole avascular necrosis. Tech Hand Up Extrem Surg 2007;11:246-58.

15. Aydın A, Araz A, Asan A. Görsel analog ölçeği ve duygu kafesi: Kültürümüze uyarlama çalışması. Türk Psikoloji Yazıları 2011;14:1-13.

16. Koldas Dogan S, Ay S, Evcik D, Baser O. Adaptation of Turkish version of the questionnaire Quick Disability of the Arm, Shoulder, and Hand (Quick DASH) in patients with carpal tunnel syndrome. Clin Rheumatol 2011;30:185-91.

17. Gras M, Mathoulin C. Vascularized bone graft pedicled on the volar carpal artery from the volar distal radius as primary procedure for scaphoid non-union. Orthop Traumatol Surg Res 2011;97:800-6.

18. Hirche C, Xiong L, Heffinger C, Münzberg M, Fischer S, Kneser U, et al. Vascularized versus non-vascularized bone grafts in the treatment of scaphoid non-union. J Orthop Surg (Hong Kong) 2017;25:2309499016684291. 
19. Sunagawa T, Bishop AT, Muramatsu K. Role of conventional and vascularized bone grafts in scaphoid nonunion with avascular necrosis: A canine experimental study. J Hand Surg Am 2000;25:849-59.

20. DellPC,BurchardtH, GlowczewskieFPJr. Aroentgenographic, biomechanical, and histological evaluation of vascularized and non-vascularized segmental fibular canine autografts. J Bone Joint Surg [Am] 1985;67:105-12.

21. Guldbrandsen CW, Radev DI, Gvozdenovic R. Normal ranges for measurements of the scaphoid bone from sagittal computed tomography images. J Hand Surg Eur Vol 2021;46:594-9.

22. Pişkin A, Cıraklı A, Erdoğan M, Göçer H, Sener M. Proksimal skafoid kaynamamalarında non-vaskülarize otogreftleme etkisiz midir? Eklem Hastalik Cerrahisi 2014;25:21-5.

23. Zhang H, Gu J, Liu H, Yuan C. Pedicled vascularized versus non-vascularized bone grafts in the treatment of scaphoid non-union: A meta-analysis of comparative studies. ANZ J Surg 2021. [Online ahead of print] 